\title{
Osteohistology of the Lower Cretaceous Yixian Formation ornithuromorph (Aves) Iteravis huchzermeyeri
}

\author{
Jingmai K. O'Connor, Min Wang, Shuang Zhou, and Zhonghe Zhou
}

\begin{abstract}
We describe for the first time the histology of an ornithuromorph bird from the Lower Cretaceous Jehol Group, revealing the bone structure of one of the oldest members of this derived clade. The newly discovered Sihedang locality of the Yixian Formation in northeastern China preserves the oldest ornithuromorph dominated avifauna, with all collected birds referable to a single taxon, Iteravis huchzermeyeri. These specimens are all preserved in a relatively greater degree of three-dimensionality compared to Jehol specimens from other localities. We sampled a specimen of Iteravis in order to test the hypothesis that this aggregation of birds may represent a breeding colony. Although medullary bone is known to facilitate three-dimensional preservation, this bone tissue was not present in the histological samples. The specimen is nearly adult with regards to skeletal fusion, and histology indicates medullary expansion had occurred and an inner circumferential layer had already formed. However, lines of arrested growth are absent. Overall the bone histology is comparable to Ichthyornis; this is consistent with the derived phylogenetic placement inferred for this new taxon relative to previously sampled basal ornithuromorphs (Patagopteryx, Hollanda), which all indicate they required more than one year to reach adulthood. This suggests that the modern avian growth strategy evolved in the Early Cretaceous in non-ornithurine birds.
\end{abstract}

Jingmai K. O'Connor. Key Laboratory of Vertebrate Evolution and Human Origins of the Chinese Academy of Sciences, Institute of Vertebrate Paleontology and Paleoanthropology, Chinese Academy of Sciences, 142 Xizhimenwai Dajie, Beijing 100044, P. R. China, jingmai@ivpp.ac.cn Min Wang. Key Laboratory of Vertebrate Evolution and Human Origins of the Chinese Academy of Sciences, Institute of Vertebrate Paleontology and Paleoanthropology, Chinese Academy of Sciences, 142 Xizhimenwai Dajie, Beijing 100044, P. R. China wangmin@ivpp.ac.cn Shuang Zhou. Key Laboratory of Vertebrate Evolution and Human Origins of the Chinese Academy of Sciences, Institute of Vertebrate Paleontology and Paleoanthropology, Chinese Academy of Sciences, 142 Xizhimenwai Dajie, Beijing 100044, P. R. China zhoushuang@ivpp.ac.cn Zhonghe Zhou. Key Laboratory of Vertebrate Evolution and Human Origins of the Chinese Academy of Sciences, Institute of Vertebrate Paleontology and Paleoanthropology, Chinese Academy of Sciences, 142 Xizhimenwai Dajie, Beijing 100044, P. R. China zhouzhonghe@ivpp.ac.cn

Keywords: Jehol; bone matrix; Ornithuromorpha; growth; Sihedang

Submission: 30 October 2014. Acceptance: 30 June 2015

O'Connor, Jingmai K., Wang, Min, Zhou, Shuang, and Zhou, Zhonghe 2015. Osteohistology of the Lower Cretaceous Yixian Formation ornithuromorph (Aves) Iteravis huchzermeyeri. Palaeontologia Electronica 18.2.35A: 1-11

palaeo-electronica.org/content/2015/1260-iteravis-histology 


\section{INTRODUCTION}

Histological analysis has recently become a popular tool among vertebrate paleontologists for understanding the biology of extinct animals. Histology is particularly useful in the study of avian evolution, given that extant birds are unique among living reptiles in being homeothermic and having rapid absolute and relative growth rates, typically reaching adult size within a year (Gill, 2007). In comparison, crocodylians, the other extant group of archosaurs, grow comparatively slowly, taking 20 to 30 years to reach skeletal maturity (Chabreck and Joanen, 1979; Hutton, 1987). Nonavian dinosaurs and basal birds grow relatively faster than crocodylians but are also known to have required several years to reach maturity, thus 'avian style' growth evolved within Aves and does not characterize its earliest members (Chinsamy et al., 1995; Erickson et al., 2007; Lee and Werning, 2008; Woodward et al., 2011). Preserved bone tissue has the ability to elucidate the transition from prolonged to rapid growth strategy that occurred within Aves during the Cretaceous (Erickson et al., 2009). However, relatively few Cretaceous bird specimens have been sampled and the evolution of this derived strategy from the dinosaurian condition is still poorly understood (Chinsamy, 2002; Erickson et al., 2009; O'Connor et al., 2014). Published samples are temporally, phylogenetically, and ontogenetically disparate so that broad evolutionary trends are obscured by potential lineage specific trends and unknown ontogenetic sequences (Chinsamy et al., 1995; O'Connor et al., 2014).

The Late Cretaceous toothed ornithurine birds Ichthyornis and Hesperornis preserve essentially modern bone tissue indicating that the unique growth strategy of living birds evolved during the Cretaceous, outside Neornithes (Chinsamy et al., 1998). Furthermore, histological analysis of most basal birds from the Early Cretaceous (e.g., Sapeornis, Jeholornis) and basal ornithuromorphs from the Late Cretaceous reveal slower forming bone tissue and lines of arrested growth (LAGs) indicating that the fully modern growth strategy evolved within the Ornithuromorpha (Chinsamy et al., 1995; Erickson et al., 2009; O'Connor et al., 2014). Attempts to further narrow down the origin of the derived rapid avian growth strategy is hindered by the limited number of sampled non-ornithurine ornithuromorphs; only two Late Cretaceous taxa have been studied thus far (Chinsamy et al., 1995; Bell et al., 2010).

The most important Mesozoic avifauna in the world is undoubtedly the prolific Lower Cretaceous
Jehol Group in northeastern China (Zhou et al., 2003). This lithologic unit preserves the most diverse Mesozoic fossil avifauna currently known to science, including the long boney-tailed jeholornithiforms, the basal pygostylian clades Confuciusornithiformes and Sapeornithiformes, and the earliest record of both ornithothoracine clades, Enantiornithes, the first major avian radiation, and its sister taxon Ornithuromorpha, the clade that includes the lineage leading to modern birds (Figure 1) (Zhou and Zhang, 2006b). The Protopteryxhorizon of the Huajiying Formation preserves the oldest known ornithuromorphs (Wang et al., 2015) and the Jehol avifauna preserves the single greatest diversity of Cretaceous Ornithuromorpha preserved anywhere in the fossil record (Zhou and Zhang, 2006b; Zhou et al., 2012), with most species represented by nearly complete specimens (Zhou and Zhang, 2001; O'Connor et al., 2010; Zhou et al., 2013). Specimens from this unit also commonly preserve integument and stomach contents, providing a huge amount of data regarding the biology of the earliest ancestors of modern birds (Zhou et al., 2012; Chiappe et al., 2014; Zheng et al., 2014).

Not surprisingly, the avifauna includes basal taxa with unusual morphologies that obfuscate their phylogenetic position (e.g., Jianchangornis, Zhongjianornis, Archaeorhynchus, Schizooura) as well as diverse clades of more derived taxa (e.g., Hongshanornithidae and Songlingornithidae) (Zhou et al., 2009; O'Connor et al., 2010; Zhou et al., 2010; Zhou et al., 2012; O'Connor and Zhou, 2013; Zhou et al., 2013; Wang et al., 2015). Despite the utility of histology for understanding basal bird biology, no ornithuromorph birds from the Jehol have been histologically studied, although every other clade has been sampled. Jeholornis, Sapeornis, and enantiornithines preserve bone formed by both woven-fibered and parallel-fibered bone marked by lines of arrested growth. This indicates that these taxa took several years to reach sexual maturity, after which they continued to grow for at least another year before reaching skeletal maturity (Figure 1, stage 1) (Erickson et al., 2009; Gao et al., 2012; O'Connor et al., 2014). The bone tissue of Confuciusornis is more heavily vascularized compared to other Early Cretaceous birds and develops an outer circumferential layer (OCL) with closely packed rest lines in adults indicating that rapid growth strategies also evolved outside the Ornithurae (Figure 1, stage 2) (Zhang et al., 1998; de Ricqlès et al., 2003). 

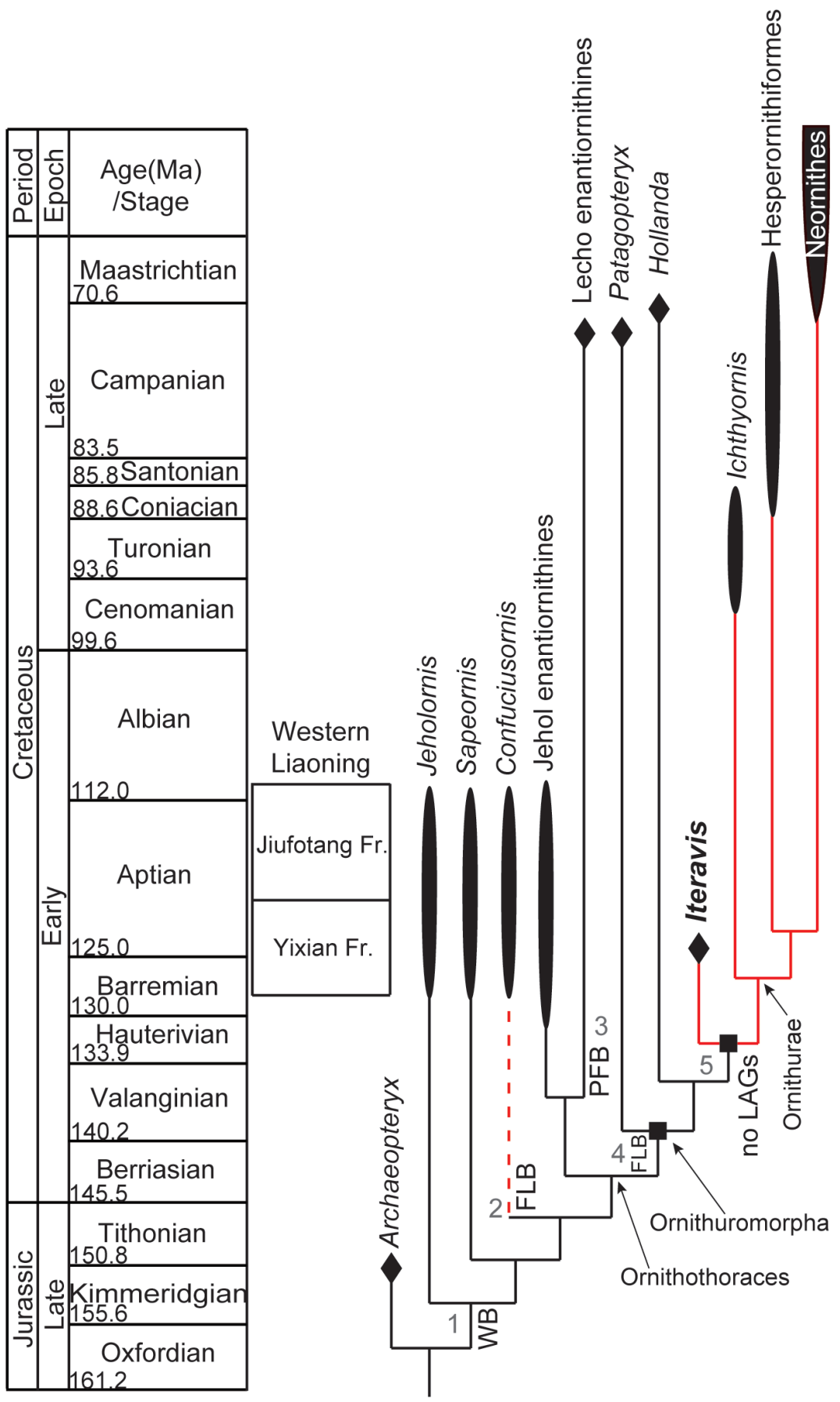

FIGURE 1. Simplified cladogram depicting relationships between specimens of Mesozoic birds that have been histologically sampled (modified from Zhou et al., 2014). Red indicates lineages in which rapid growth evolved; the dashed line for Confuciusornis is to indicate that although growing relatively faster than other basal birds, this taxon did not achieve growth rates comparable to derived members of the ornithuromorph lineage. Stages 1-5 (grey numbers) refer to important evolutionary transitions in basal bird bone microstructure: 1 , bone shows increased vascularity and a primarily woven matrix but growth is non-continuous; 2, the Confuciusornis lineage evolves at least a period of postnatal growth in which fibro-lamellar bone is formed and growth lines are only found in the outermost cortex indicating these birds approached adult size within the first year; 3 , at least one lineage of Late Cretaceous enantiornithines evolves a slow and protracted growth strategy; 4, fibro-lamellar bone matrix indicative of more rapid growth appears in ornithuromorphs but growth lines persist; 5 , derived ornithuromorphs evolve uninterrupted growth. Abbreviations: FLB, fibro-lamellar bone; LAG, line of arrested growth; PFB, parallel fibered bone; WB, woven bone. 
Only two non-ornithurine ornithuromorphs have been sampled, both from the CampanianMaastrichtian (83-65.5 Ma), the latest stages of the Late Cretaceous: Patagopteryx from the Lecho Formation in Argentina (Chinsamy et al., 1994) and Hollanda from the Barun Goyot Formation in Mongolia (Bell et al., 2010). Like ornithurines (Ichthyornis and Hesperornis), these taxa preserve fibrolamellar bone indicative of rapid growth rates. However, like more primitive birds, these taxa also preserve LAGs and parallel-fibered bone, indicating that the derived growth strategy evolved among more derived ornithuromorphs outside Ornithurae (Figure 1, stage 4) (Chinsamy et al., 1994; Bell et al., 2010). Of the wealth of specimens from the Jehol Group, most are phylogenetically intermediate between Patagopteryx and ornithurines (O'Connor et al., 2011) and thus have the potential to shed light on the final stages in the evolution of derived avian growth rates. Here we describe the first histological sections from a Yixian Formation ornithuromorph, Iteravis huchzermeyeri (Zhou et al., 2014), which is approximately 55-50 m.y. older than previously sampled ornithuromorph taxa (e.g., Hollanda, Patagopteryx)(Dashzeveg et al., 2005) and the first taxon sampled from the Early Cretaceous.

This taxon was chosen for several reasons. Iteravis is resolved as the most derived Jehol ornithuromorph, falling in a polytomy outside Ornithurae, the derived clade of birds formed by Hesperornithiformes + Neornithes (Chiappe, 1991), while other Jehol ornithuromorphs are resolved basal to this polytomy and near the phylogenetic position of Hollanda (Figure 1) (Zhou et al., 2014). Secondly, this taxon is found only in the 128 Ma Yixian Formation; only two specimens, both referable to the hongshanornithid ornithuromorph Archaeornithura, are older and their preserved bone tissue is unsuitable for histological analysis (Wang et al., 2015). In addition, Iteravis has only been collected from the Sihedang locality, which is dominated by this taxon. Like large groups of Confuciusornis preserved together, this aggregation of a single taxon has been suggested to be indicative of social behavior (Zhou et al., 2014). Lastly, specimens of Iteravis are nearly all preserved three dimensionally, which is unusual among Jehol specimens. Because three-dimensional preservation of bone is in some cases to be facilitated by the presence of medullary bone (O'Connor, personal obs.), Zhou et al. (2014) hypothesized that the large number of Iteravis collected at Sihedang may represent a breeding colony. In order to test the latter hypoth- esis we sectioned the holotype of Iteravis huchzermeyeri IVPP V18958 (Zhou et al., 2014, figure 1; Figure 2) for histological analysis. We describe the results and discuss the implications of this bone tissue morphology on our understanding of the derived avian growth strategy.

\section{METHODS}

Histological samples were taken from the midshafts of the right ulna and tibiotarsus using a microsaw. Bone samples were embedded in EXAKT Technovit 7200 (Norderstedt, Germany) one-component resin, and cured for 24 hours. The samples were cut transversely using an EXAKT $300 \mathrm{CP}$ accurate circular saw, and were then ground and polished using the EXAKT 400CS grinding system (Norderstedt, Germany) until the desired optical contrast was reached. The histological sections were observed under both normal/ regular and elliptically polarized light using a ZEISS AX10 light microscope (Thornwood, U.S.A.). Photographs were taken using the ZEISS AxioCam MRc5 (Thornwood, U.S.A.) and Leica Image Manager [1.20]. We used the "photomerge" tool in Adobe Photoshop CS5 [v.12.0] to reconstruct the entire section. Cortical thickness was measured using CorelDRAW X3. Histological terminology primarily follows Erickson et al., (2009).

\section{DESCRIPTION}

The bone wall of the ulna is thin and measures approximately $0.16 \mathrm{~mm}$ in transverse section (Figure 3.1). The thickness is not even and swells at two points located roughly opposite each other, one located caudodorsally and the other cranioventrally, where the thickness is an estimated 0.18 $\mathrm{mm}$ thick (thinnest areas measure $0.14 \mathrm{~mm}$ ). Although crushed, the medullary cavity is devoid of any signs of cancellous bone tissue except for one thin caudoventrally located fragment (Figure 3.1). Although this may represent a trabecular strut (Chinsamy et al., 1995), we consider it more likely to be a displaced fragment of the ICL. The medullary cavity is lined by a thin layer of avascular, endosteally derived lamellar bone (the inner circumferential layer, ICL). Distinct lamellae are visible under polars (Figures 3.3, 3.4). This endosteal layer varies in thickness but only accounts for $1 / 10-1 / 20$ the thickness of the cortex. The ICL is separated from the rest of the bone matrix by a tide line that erodes some primary osteons, indicating that medullary expansion had occurred prior to deposition of the ICL. The bone is primarily formed 


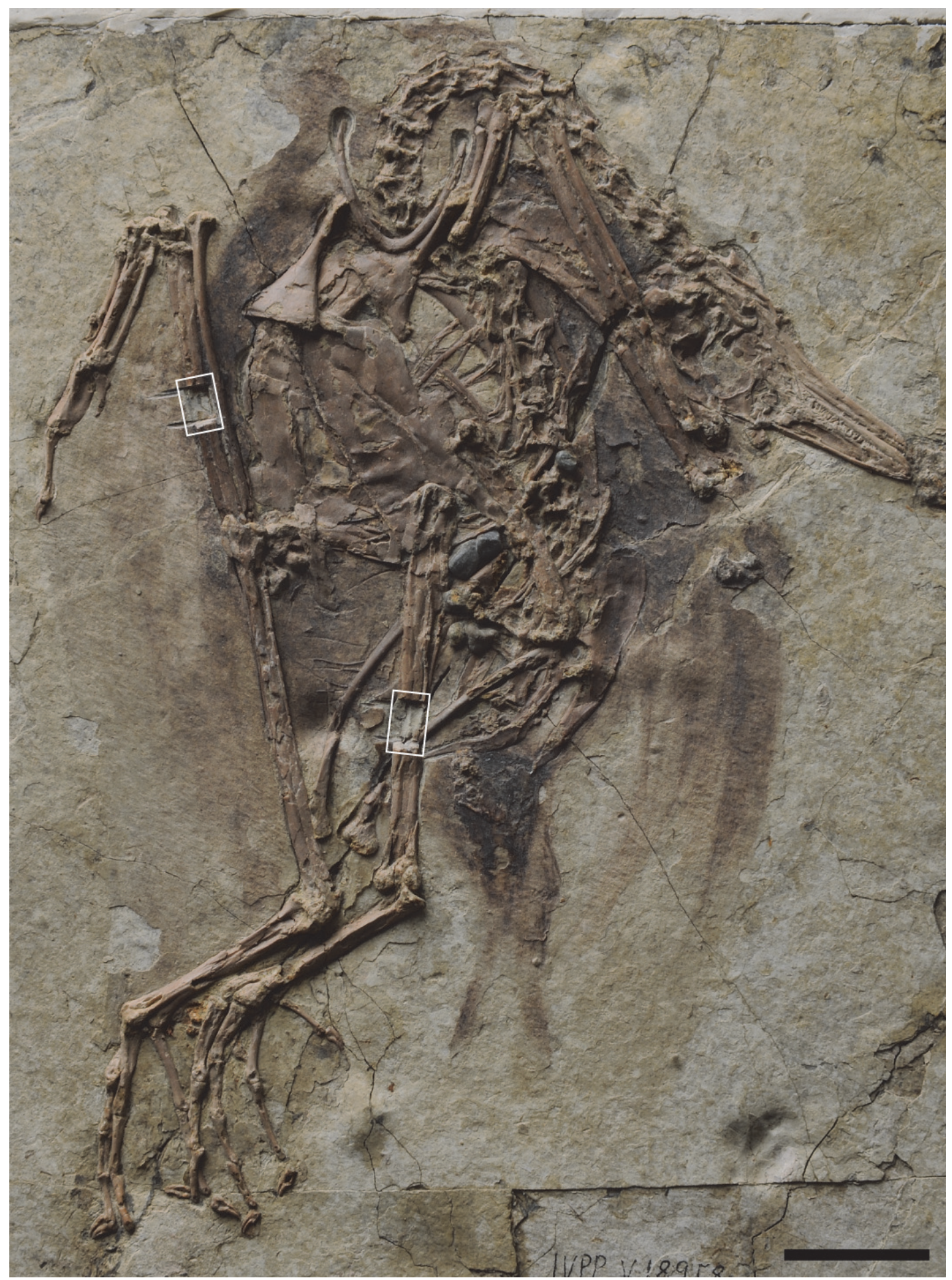

FIGURE 2. Photograph of the holotype of Iteravis huchzermeyeri IVPP V18958 after sampling (indicated by white boxes); scale bar equals 2 centimeters.

by unremodeled fibro-lamellar matrix. Vascularization is primarily longitudinal, although radial and oblique canals are also observed, concentrated in the dorsal quadrant. Secondary osteons are absent. The osteocyte lacunae are relatively flattened and oriented parallel to the medullary cavity within the ICL, whereas they are more globular and randomly oriented in the outer cortex. Lamellated 

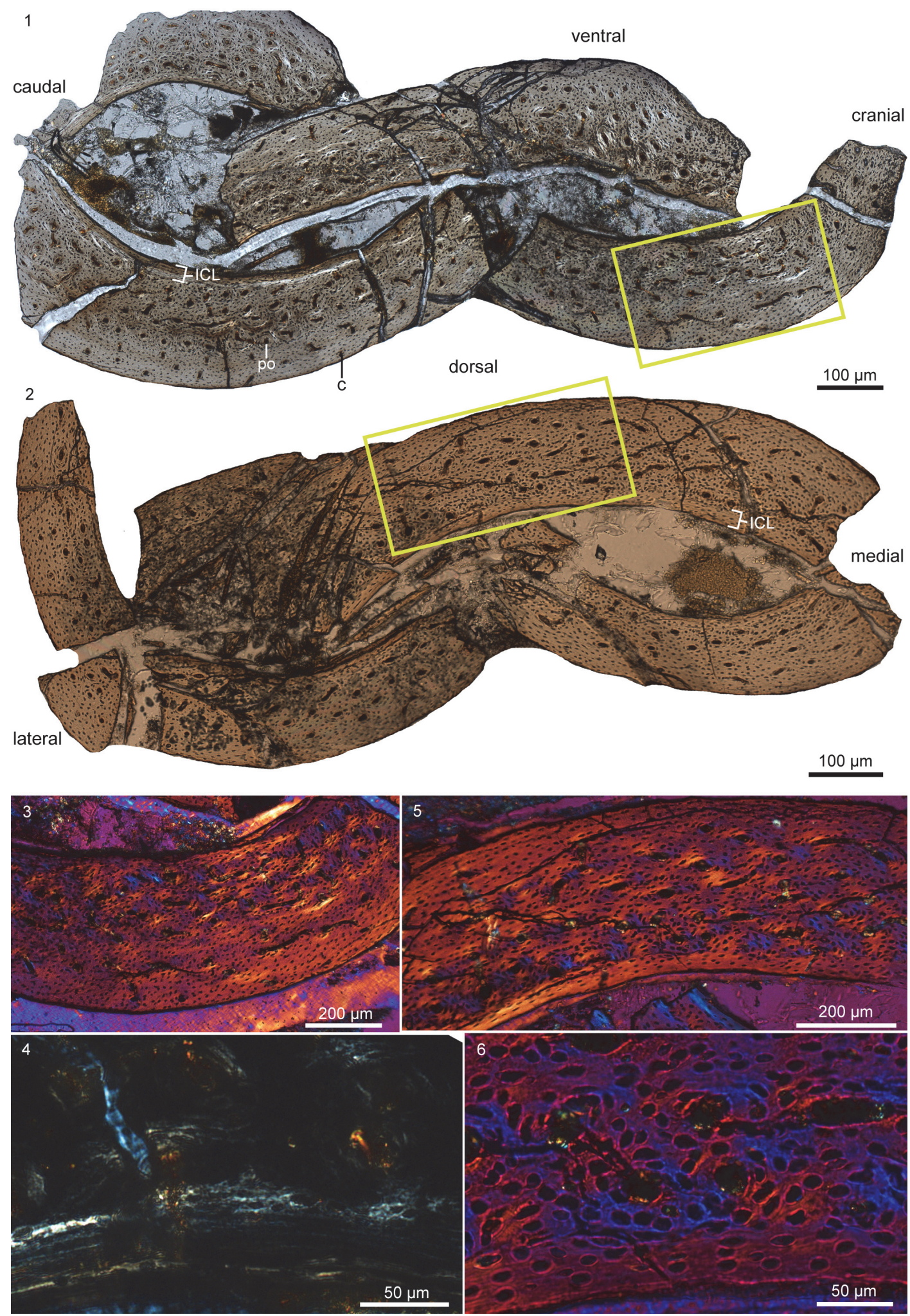

FIGURE 3. Histological sections taken from Iteravis huchzermeyeri IVPP V18958: 1, ulna; 2, tibiotarsus; 3, close up of denoted area of the ulna ; 4, close up of the contact with the endosteal layer under cross polarized light showing presence of lamellae; 5 , close up of denoted area of the tibiotarsus; 6 , close up of the tibiotarsus under cross polarized light showing the endosteal layer is parallel fibered. Abbreviations: c, simple canal; icl, inner circumferential layer; po, primary osteon. 
bone is observed around the canals in the primary osteons (Figures 3.3, 3.4). Vascularization is heavily reduced in the outer region of the cortex, and no primary osteons are present indicating a reduction in growth rate; the thickness of this outer layer of woven-fibered bone varies throughout the circumference ranging from $10-35 \%$ the thickness of the cortex. Two canals reach the periosteal surface indicating that growth was not complete. Although a distinct outer circumferential layer (OCL) like that present in living birds is not present, the osteocyte lacunae become increasingly organized approaching the periosteal surface, becoming relatively more flattened and arranged parallel to the medullary cavity so that parallel-fibered bone forms the outermost cortex. The ulnar histology of IVPP V18958 indicates a steady and rapid decrease in growth rate prior to death. Overall the section is very similar to reports from a humeral section of Ichthyornis (Chinsamy et al., 1998, figure 3) except that in this taxon the ICL is proportionately thicker (slightly thicker than the thickest areas in the ulnar section of IVPP V18958) in the figured part of the cortex.

The cortical thickness of the tibiotarsus varies throughout the transverse section; the cortex is thinner than the ulna and measures approximately $0.15 \mathrm{~mm}$ in the thickest region and $0.10 \mathrm{~mm}$ in the thinnest region. It appears to be thicker along the dorsal surface. Compared to the ulna, the ICL is on average proportionally thicker (15-20\%), there are fewer radial and oblique canals, and the matrix is generally less highly vascularized consisting primarily of woven bone (Figures 3.2, 3.5). Like the ulna the outer region of the cortex is less vascularized; this outer layer is proportionately thicker where the bone wall is thin. The outer $5-10 \%$ of the cortex is formed by parallel-fibered bone, in which the osteocyte lacunae are visibly flattened and arranged parallel to the surface of the bone. Generally bone formation appears to have been slower in the tibiotarsus compared to the ulna. However, the endosteal layer is parallel-fibered; the osteocyte lacunae remain quite fat globular and no lamellae are visible under crossed-polars (Figure 3.6).

\section{DISCUSSION}

The Jehol avifauna preserves representatives of the entire phylogenetic spectrum of known Early Cretaceous birds (Zhou and Zhang, 2006b) and with the exception of the Ornithuromorpha, all groups have been previously histologically sampled (de Ricqlès et al., 2003; Erickson et al., 2009;
Gao et al., 2012; Zhang et al., 2013; O'Connor et al., 2014); these studies cumulatively reveal that like non-avian dinosaurs most Early Cretaceous birds required several years to reach adult size and became reproductively active (often marked by a double LAG) before somatic maturity. However, the study of Early Cretaceous bird osteohistology is still in its early stages; sample sizes are low (e.g., Ichthyornis $\mathrm{n}=$ one specimen/sample, Jeholornis $\mathrm{n}$ = two specimens, three samples) and increased sampling within groups continues to modify our understanding (O'Connor et al., 2014). For example, the bone of Confuciusornis is typically described as fibro-lamellar (Zhang et al., 1998; de Ricqlès et al., 2003; Chinsamy et al., 2013) but is also regarded as woven-fibered (Erickson et al., 2009). We have sampled a new Confuciusornis specimen (STM13-40; unpublished), and based on our observations we concur with Erickson et al. (2009) that the bone matrix, although heavily vascularized, is primarily woven-fibered. However, fibro-lamellar (forming approximately one fifth of the cortex, eroded by medullary expansion prior to the deposition of the thick ICL of lamellar bone) and parallel-fibered (forming the outer fifth of the cortex, between the LAG and OCL) matrix is also present in most long bone sections. Given that basal bird ontogenies are unknown and potentially complex, such apparent disagreements in the published record will surely receive clarification through future studies especially on ontogenetic sequences of individual taxa.

IVPP V18958 is the first Jehol ornithuromorph to be studied histologically and thus also the oldest member of this clade to be sectioned thus far. The only other non-ornithurine ornithuromorphs that have been sampled are the Late Cretaceous Campanian-Maastrichtian taxa, Hollanda, and Patagopteryx (Figure 1). The latter taxon is considered to be a secondarily flightless bird and, despite its latest Cretaceous age, was considered the most basal known ornithuromorph until the discovery of Archaeorhynchus from the Jehol Group (Chiappe, 2002; Zhou and Zhang, 2006a); now Patagopteryx is usually resolved in a polytomy with primitive Jehol ornithuromorphs, with Archaeorhynchus outside this polytomy as the most basal member of the clade (O'Connor et al., 2011; O'Connor and Zhou, 2013). A single femur referable to Patagopteryx (MACN-N-03) has been sampled osteohistologically. The cortex is formed nearly entirely by fibro-lamellar bone matrix. A single LAG interrupts growth about midcortex; this is preceded by an annulus of lamellated bone matrix. The inner 
cortex is heavily remodeled with secondary osteons present. A thin ICL erodes this layer (Chinsamy et al., 1995).

Hollanda is known only from hindlimb elements and is typically resolved as more derived than Jehol ornithuromorphs (O'Connor and Zhou, 2013) with the exception of Iteravis (Zhou et al., 2014), although because of the fragmentary nature of the only known specimen the phylogenetic position of this taxon is not stable (Bell et al., 2010). The tibiotarsal sample reveals primarily parallelfibered bone matrix with local areas of heavy reticular vascularization. A single LAG is present in the outer cortex and an annulus lies just within the periosteal surface. No ICL is present in the tibiotarsus of Hollanda, although its scalloped interior margin indicates some medullary expansion had occurred. This specimen is considered to have died during a transitional stage in its histological development perhaps during medullary resorption but prior to the deposition of the ICL (Bell et al., 2010). The osteohistology of the derived Late Cretaceous ornithurine birds Ichthyornis and Hesperornis has also been described (Chinsamy et al., 1998). A single humeral fragment assigned to Ichthyornis (KUVP 2294) reveals continuous fibrolamellar bone matrix. Hesperornis samples $(\mathrm{n}=$ six, femora and tibiotarsi; the forelimb is heavily reduced) reveal continuous bone deposition with an OCL present in adults (Chinsamy et al., 1998; Wilson and Chin, 2014).

Both the ulna and tibiotarsus were sampled from IVPP V18958 (Figure 2), whereas only hindlimb elements are available for comparison in basal ornithuromorphs Patagopteryx and Hollanda. The tibiotarsus of Iteravis IVPP V18958 is thinner and less vascularized compared to the ulna, also observed between hindlimb and forelimb elements in Jeholornis and Jehol enantiornithines (O'Connor et al., 2014). Differences between the bone matrix of the ulna and tibiotarsus in Iteravis highlight the importance of sampling multiple elements where possible. The ulnar bone in IVPP V18958 is much more heavily vascularized than other sampled Early Cretaceous birds with the exception of Confuciusornis, which appears to have evolved accelerated growth rates in parallel to the ornithuromorph lineage (A.J. de Ricqlès et al., 2003). Neither the ulna nor the tibiotarsus in IVPP V18958 preserves lines of arrested growth (LAGs) or a distinct OCL, although the decrease in vascularity near the periosteal surface indicates that growth had significantly slowed prior to death. This decrease in vascularization is also observed in Ich- thyornis KUVP 2294. The ICL is typically formed when growth is nearly complete, just prior to the formation of the OCL (Chinsamy, 1995). This histology suggests that IVPP V18958 was a fairly mature subadult individual approaching skeletal maturity. This is consistent with osteological evidence such as the incomplete fusion of the proximal carpometacarpus and potentially the caudal midline of the sternum. The fairly small size range of all collected specimens of Iteravis (tarsometatarsus length varies from 32-36 mm; J.K. O'Connor, personal obs.) suggests that IVPP V18958 (tarsometatarsus measures $31 \mathrm{~mm}$ ) was near full grown and not likely to greatly increase in size. Based on these observations we do not necessarily expect the deposition of future LAGs, only the likely formation of an OCL, as in living birds. Although an OCL appears to be absent in the single sampled specimen of Ichthyornis (KUVP-2294) (Chinsamy et al., 1998) and Patagopteryx (MACN$\mathrm{N}-03$ ), the presence of an OCL in Hesperornis (Wilson and Chin, 2014) and all crown birds suggests the absence of this layer in the sampled specimens of Iteravis, Patagopteryx, and Ichthyornis is likely due to ontogenetic immaturity (Chinsamy et al., 1995). Additionally, the relatively thin ICL observed in Iteravis IVPP V18958, compared to KUVP 2294, may reflect ontogenetic immaturity. Although the thickness of this feature varies between sampled elements and individual specimens, the ICL when present is proportionately thicker in basal birds, sometimes forming more than one third the thickness of the cortex (Sapeornis, Jeholornis, Early Cretaceous enantiornithines) (Chinsamy et al., 2013; O'Connor et al., 2014). A proportionately thin $\mathrm{ICL}$ is also found in sampled Late Cretaceous enantiornithines (Chinsamy et al., 1995). A proportionately thin ICL may be a derived feature evolved in parallel by enantiornithine and ornithuromorph birds. However, given that most sampled specimens are not considered to be fully mature, additional sampling is required in order to test this hypothesis.

Both the ulna and tibiotarsus of Iteravis IVPP V18958 preserve uninterrupted bone tissue and an ICL separated by a tide line indicating that medullary resorption and deposition of the ICL occurred within less than a year of growth. Other Cretaceous non-ornithurine ornithuromorphs Patagopteryx and Hollanda each preserve at least one growth line; the two types of growth lines, LAGs and annuli, are inferred to be deposited annually (Francillon-Viellot et al., 1990). Hollanda preserves a single LAG followed by an annulus and no ICL clearly indicating 
that this taxon took over two years to reach maturity. Patagopteryx MACN-N-03 is interrupted by a single LAG and the absence of an OCL suggests this specimen is also not quite somatically mature (Chinsamy et al., 1995). The presence of an ICL, parallel-fibered bone near the periosteal surface, and the absence of LAGs may suggest the Iteravis lineage reached skeletal maturity within a year, as in most living birds (Figure 1, stage 5). Until now only the more derived, ornithurines, Hesperornis and Ichthyornis, preserve uninterrupted bone formation as in most neornithines (Chinsamy et al., 1998; Wilson and Chin, 2014). This pattern is consistent with the results of the cladistic analysis, which resolves Iteravis as more derived than Patagopteryx and Hollanda as well as all Jehol ornithuromorphs, with Apsaravis + Ambiortus, Gansus, and Iteravis forming successive outgroups to Ornithurae; in trees one step longer, these taxa all form a polytomy with Neornithes and Hesperornithiformes (Zhou et al., 2014)(Figure 1). We predict that other more basal Jehol ornithuromorphs may preserve LAGs, as in Patagopteryx and Hollanda. Despite its phylogenetic position as more derived than Hollanda and Patagopteryx, Iteravis is approximately 50-55 m.y. older than either taxon. The presence of the derived avian growth strategy in Iteravis from the $128 \mathrm{Ma}$ Yixian Formation, the second oldest layer to preserve ornithuromorph remains, indicates that this feature evolved early in a derived subset of ornithuromorphs. Basal lineages apparently retained primitive growth strategies, as evident from the presence of LAGs in Hollanda and Patagopteryx although alternatively, this feature may be secondarily evolved in the flightless Patagopteryx. Some living birds have prolonged growth (Bourdon et al., 2009).

In addition to being largely referable to Iteravis, specimens from Sihedang are also notable in that they preserve a greater degree of threedimensionality than is typical of Jehol specimens. The presence of medullary bone in reproductively active females has been observed to facilitate three-dimensional preservation in some specimens (J.K. O'Connor, personal obs.). Therefore, this potentially may represent a breeding or nesting colony (Zhou et al., 2014). We sampled IVPP V18958 in order to test this hypothesis. The wellpreserved cross-section clearly lacks medullary bone (Figure 3). However, given the absence of an OCL in IVPP V18958, several more adult specimens of Iteravis would have to be sampled in order to rigorously test this hypothesis. Although basal birds appear to reach sexual maturity before skele- tal maturity (O'Connor et al., 2014), the opposite is true of living birds (Gill, 2007). The condition in basal ornithuromorphs is unknown; however, because the advent of reproductive maturity is typically associated with a double LAG, it is likely that Iteravis became reproductively active after reaching somatic maturity as in neornithines. The absence of medullary bone in IVPP 18958 could be due either to gender or ontogeny. Although the specimen may appear slightly more three-dimensional than most specimens, it is clear from the sections (Figure 3 ) that bone preservation is not as pristine as described - although complete the bone is still crushed in on itself, not preserving the integrity of the cross-section of the shaft. Although the breeding colony hypothesis should be further tested through additional sampling, we suggest that the three-dimensional preservation of Sihedang specimens is more likely the result of taphonomic processes.

\section{CONCLUSIONS}

The holotype of Iteravis huchzermeyeri is the first Jehol ornithuromorph and oldest member of this clade to be studied osteohistologically thus far. The cortex of the ulna and tibiotarsus reveal uninterrupted growth similar to the sampled specimen of Ichthyornis and most living birds. The ulnar sample primarily reveals fibro-lamellar bone matrix but deposition slows throughout the outer cortex. The preserved bone matrix indicates the tibiotarsus grew slower than the ulna. The presence of a tide line indicating medullary resorption and an ICL together with the absence of growth lines in IVPP V18958 strongly suggests that Iteravis reached adult size within a year, as in the Ornithurae. The presence of growth lines in basal ornithuromorphs from the Late Cretaceous suggests that, although the derived growth strategy appeared relatively early in ornithuromorph evolution, some lineages retained primitive strategies. Due to the absence of an OCL in IVPP V18958, histological analysis of this specimen fails to provide resolution to the hypothesis that Sihedang may represent a colonial breeding site.

\section{ACKNOWLEDGEMENTS}

We thank S.-K. Zhang for assistance preparing the histological samples and S. Werning and D. Evans for their useful comments on an earlier version of this manuscript. This research was supported by the National Science Foundation of 
China (KN212101) and the Chinese Academy of Sciences.

\section{REFERENCES}

Bell, A., Chiappe, L.M., Erickson, G.M., Suzuki, S., Watabe, M., Barsbold, R., and Tsogtbaatar, K. 2010. Description and ecologic analysis of a new Late Cretaceous bird from the Gobi Desert (Mongolia). Cretaceous Research, 31:16-26.

Bourdon, E., Castanet, J., de Ricqles, A.J., Scofield, P., Tennyson, A., Lamrous, H., and Cubo, J. 2009. Bone growth marks reveal protracted growth in New Zealand kiwi (Aves, Apterygidae). Biology Letters, 5(3):14.

Chabreck, R.H. and Joanen, T. 1979. Growth rates of American alligators in Louisiana. Herpetologica, 35:51-57.

Chiappe, L.M. 1991. Cretaceous birds of Latin America. Cretaceous Research, 12:55-63.

Chiappe, L.M. 2002. Basal bird phylogeny: problems and solutions, p. 448-472. In Chiappe, L.M. and Witmer, L.M. (eds.), Mesozoic Birds: Above the Heads of Dinosaurs. University of California Press, Berkeley.

Chiappe, L.M., Bo, Z., O'Connor, J.K., Gao, C.-H., Wang, X.-R., Habib, M., Marugán-Lobón, J., Meng, Q.-J., and Zheng, X.-D. 2014. A new specimen of the Early Cretaceous bird Hongshanornis longicresta: insights into the aerodynamics and diet of a basal ornithuromorph. PeerJ, 2:e234.

Chinsamy, A. 1995. Histological perspectives on growth in the birds Struthio camelius and Sagittarius serpentarius, p. 317-323. In Peters, D.S. (ed.), Acta Palaeornithologica. Courier Forschungsinstitut Senckenberg

Chinsamy, A. 2002. Bone microstructure of early birds, p. 421-431. In Chiappe, L.M. and Witmer, L.M. (eds.), Mesozoic Birds: Above the Heads of Dinosaurs. University of California Press, Berkeley.

Chinsamy, A., Chiappe, L.M., and Dodson, P. 1994. Growth rings in Mesozoic birds. Nature, 368:196197.

Chinsamy, A., Chiappe, L.M., and Dodson, P. 1995. Mesozoic avian bone microstructure: physiological implications. Paleobiology, 21(4):561-574.

Chinsamy, A., Chiappe, L.M., Marugán-Lobón, J., Gao, C.-H., and Zhang, F.-J. 2013. Gender identification of the Mesozoic bird Confuciusornis sanctus. Nature Communications, DOI: 10.1038/ncomms2377.

Chinsamy, A., Martin, L.D., and Dodson, P. 1998. Bone microstructure of the diving Hesperornis and the volant Ichthyornis from the Niobrara Chalk of western Kansas. Cretaceous Research, 19:225-235.

Dashzeveg, D., Dingus, L., Loope, D.B., Swisher, C.C., Dulam, T., and Sweeney, M.R. 2005. New stratigraphic subdivision, depositional environment, and age estimate for the Upper Cretaceous Djadokhta Formation, southern Ulan Nur Basin, Mongolia. American Museum Novitates, 3498:1-31. de Ricqlès, A. 1976. Recherches paléohisologiques sur les os longs des tétrapodes VII. - Sur la classification, la signification fonctionnelle et l'histoire des tissus osseux de tétrapodes (deuxième partie). Annales de Paléontologie (Vertébrés), 62(1):71-126.

de Ricqlès, A.J., Padian, K., Horner, J.R., Lamm, E.-T., and Myhrvold, N. 2003. Osteohistology of Confuciusornis sanctus (Theropoda: Aves). Journal of Vertebrate Paleontology, 23(2):373-386.

Erickson, G.M., Rauhut, O.W.M., Zhou, Z.-H., Turner, A.H., Inouye, B.D., Hu, D.-Y., and Norell, M.A. 2009. Was dinosaurian physiology inherited by birds? Reconciling slow growth in Archaeopteryx. PLOS ONE, 4(10):e7390.

Erickson, G.M., Rogers, K.C., Varricchio, D.J., Norell, M.A., and Xu, X. 2007. Growth patterns in brooding dinosaurs reveals the timing of sexual maturity in non-avian dinosaurs and genesis of the avian condition. Biology Letters, 3:558-561.

Francillon-Viellot, H., De Buffrénil, V., Castanet, J., Géraudie, J., Meunier, F.J., Sire, J.Y., Zylberberg, L., and de Ricqlès, A.J. 1990. Microstructure and mineralization of vertebrate skeletal tissues, p. 471-530. In Carter, J.G. (ed.), Skeletal Biomineralization: Patterns, Processes and Evolutionary Trends, Volume I. Van Nostrand Reinhold, New York.

Gao, C.-H., Chiappe, L.M., Zhang, F.-J., Pomeroy, D.L., Shen, C.-Z., Chinsamy, A., and Walsh, M.O. 2012. A subadult specimen of the Early Cretaceous bird Sapeornis chaoyangensis and a taxonomic reassessment of sapeornithids. Journal of Vertebrate Paleontology, 32(5):1103-1112.

Gill, F.B. 2007. Ornithology, 3rd Edition. W.H. Freeman and Company, New York.

Hutton, J. 1987. Growth and feeding ecology of the Nile crocodile Crocodylus niloticus at Ngezi, Zimbabwe. The Journal of Animal Ecology:25-38.

Lee, A.H. and Werning, S. 2008. Sexual maturity in growing dinosaurs does not fit reptilian growth models. Proceedings of the National Academy of Sciences, 105(2):582-587.

O'Connor, J.K., Chiappe, L.M., and Bell, A. 2011. Premodern birds: avian divergences in the Mesozoic, $p$. 39-114. In Dyke, G.D. and Kaiser, G. (eds.), Living Dinosaurs: the Evolutionary History of Birds. J. Wiley \& Sons, New Jersey.

O'Connor, J.K., Gao, K.-Q., and Chiappe, L.M. 2010. A new ornithuromorph (Aves: Ornithothoraces) bird from the Jehol Group indicative of higher-level diversity. Journal of Vertebrate Paleontology, 30(2):311321.

O'Connor, J.K., Wang, M., Zheng, X.-T., Wang, X.-L., and Zhou, Z.-H. 2014. The histology of two female Early Cretaceous birds. Vertebrata Palasiatica, 52(1):112-128.

O'Connor, J.K., and Zhou, Z.-H. 2013. A redescription of Chaoyangia beishanensis (Aves) and a comprehensive phylogeny of Mesozoic birds. Journal of Systematic Palaeontology, 11(7):889-906. 
Wang, M., Zheng, X.-T., O'Connor, J.K., Lloyd, G.T., Wang, X.-L., Wang, Y., Zhang, X.-M., and Zhou, Z.-H. 2015. The oldest record of Ornithuromorpha reveals heterogeneous rates of morphological evolution among Early Cretaceous birds. Nature Communications, 6:6987.

Wilson, L.E. and Chin, K. 2014. Comparative osteohistology of Hesperornis with reference to pygoscelid penguins: the effects of climate and behaviour on avian bone microstructure. Royal Society Open Science, 1(140245):1-16.

Woodward, H.N., Horner, J.R., and Farlow, J.O. 2011. Osteohistological evidence for determinate growth in the American Alligator. Journal of Herpetology, 45(3):339-342.

Zhang, F., Hou, L., and Ouyang, L. 1998. Osteological microstructure of Confuciusornis: preliminary report. Vertebrata PalAsiatica, 36(2):126-135.

Zhang, Z.-H., Chiappe, L.M., Han, G., and Chinsamy, A. 2013. A large bird from the Early Cretaceous of China: new information on the skull of enantiornithines. Journal of Vertebrate Paleontology, 33(5):1176-1189.

Zheng, X.-T., O'Connor, J.K., Huchzermeyer, F.W., Wang, X.-L., Wang, Y., Zhang, X.-M., and Zhou, Z.-H. 2014. New specimens of Yanornis indicate a piscivorous diet and modern alimentary canal. PLOS ONE, 9(4):e95036.

Zhou, S., O'Connor, J.K., and Wang, M. 2014. A new species from an ornithuromorph dominated locality of the Jehol Group. Chinese Science Bulletin, 59(36):5366-5378.

Zhou, S., Zhou, Z.-H., and O'Connor, J.K. 2012. A new toothless ornithurine bird (Schizooura lii gen. et sp. nov.) from the Lower Cretaceous of China. Vertebrata PalAsiatica, 50(1):9-24.

Zhou, S., Zhou, Z.-H., and O'Connor, J.K. 2013. Anatomy of the Early Cretaceous Archaeorhynchus spathula. Journal of Vertebrate Paleontology, 33(1):141-152.

Zhou, Z., Barrett, P.M., and Hilton, J. 2003. An exceptionally preserved Lower Cretaceous ecosystem. Nature, 421:807-814.

Zhou, Z. and Zhang, F. 2001. Two new ornithurine birds from the Early Cretaceous of western Liaoning, China. Chinese Science Bulletin, 46(15):1258-1264.

Zhou, Z.-H. and Zhang, F.-C. 2006a. A beaked basal ornithurine bird (Aves, Ornithurae) from the Lower Cretaceous of China. Zoologica Scripta, 35(4):363373.

Zhou, Z.-H. and Zhang, F.-C. 2006b. Mesozoic birds of China - a synoptic review. Vertebrata PalAsiatica, 44(1):74-98.

Zhou, Z.-H., Zhang, F.-C., and Li, Z.-H. 2009. A new basal orithurine (Jianchangornis microdonta gen. et sp. nov.) from the Lower Cretaceous of China. Vertebrata PalAsiatica, 47(4):299-310.

Zhou, Z.-H., Zhang, F.-C., and Li, Z.-H. 2010. A new lower cretaceous bird from China and tooth reduction in early avian evolution. Proceedings of the Royal Society of London B, 277(1679):219-227. 